\title{
FILOSOFIA E EDUCABILIDADE HUMANA: ENTREVISTA COM WOLFDIETRICH SCHMIED-KOWARZIK
}

\author{
Claudio A. Dalbosco ${ }^{1}$
}

\section{Introdução}

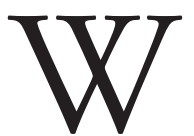

olfdietrich Schmied-Kowarzik nasceu em 11 de março de 1939, em Friedberg (Alemanha). Fez sua tese de doutorado na Universidade de Viena, na Aústria, em 1963. Realizou seu trabalho de livre-docência, na área de Filosofia da Educação, sob a orientação de Josef Derbolav, em 1970, na Universidade de Bonn (Alemanha). Posteriormente, ainda no mesmo ano, assumiu vaga, como Professor, na recém-formada Escola Superior Integrada de Kassel (Alemanha), onde exerceu atividades de docência e de pesquisa até se aposentar, em 2007. Além de suas investigações filosóficas e pedagógicas, orientou, em estreita parceria com o prof. Hans-Georg Flickinger ${ }^{2}$, os estudos de doutorado de vários brasileiros, entre os quais se destacam Muriel Maia-Flickinger (Universidade Federal do Rio Grande do Sul - UFRGS), Rodrigo Duarte (Universidade Federal de Minas Gerais - UFMG), Draiton G. De Souza (Pontifícia Universidade Católica do Rio Grande do Sul - PUCRS), Claudio A. Dalbosco (Universidade de Passo Fundo - UPF/RS), Rosalvo Schütz (Universidade do Oeste Paulista - UNOESTE) e Eduardo Chagas (Universidade Federal do Ceará - UFCE). Encontram-se traduzidos para o português dois de seus livros: Pedagogia dialética, pela Editora Brasiliense (SCHMIED-KOWARZIK, 1988) e Práxis e responsabilidade, pela Editora EDIPUCRS (SCHMIED-KOWARZIK, 2002) e vários outros ensaios.

Herdeiro de uma ampla formação clássica, Schmied-Kowarzik contou, em seus anos de universidade, com o estudo sistemático de autores como Platão, Georg Wilhelm Friedrich Hegel, Johann Friedrich Herbart, Friedrich Schleimacher, Friedrich Wilhelm Joseph von Schelling e Karl Marx, para citar apenas alguns. Conseguiu alcançar em suas famosas preleçóes, proferidas durante décadas na Universidade de Kassel, uma combinação rara e de efeito pedagógico

\footnotetext{
${ }^{1}$ Universidade de Passo Fundo, Programa de Pós-Graduação em Educação - Passo Fundo (RS), Brasil. E-mail: vcdalbosco@hotmail.com DOI: 10.1590/ES0101-73302016158327
} 
extraordinário, entre profundidade e simplicidade na exposição. Quem teve a oportunidade de ser seu aluno, desenvolvendo a escuta silenciosa ativa, saia de suas aulas transformado e motivado para dar continuidade aos estudos. Também era agradável e estimulador ouvi-lo como conferencista e grande orador, sobretudo nas sessóes de estudo do Grupo de Trabalho Interdisciplinar para Problemas de Fundamentação Filosófica da Ciência e da Práxis (IAG). Ali, reuniam-se, além de professores e alunos (doutorandos) da Universidade de Kassel, também professores convidados de outras universidades alemãs e estrangeiras. As sessōes eram verdadeiros exercícios de interdisciplinariedade, certamente marcantes para todos os doutorandos que tiveram a oportunidade de frequentá-las.

Da vasta produção intelectual do prof. Wolfdietrich Schmied-Kowarzik cabe destacar - e isto aparece de maneira clara na entrevista — sua interpretaçáo do pensamento de Schleiermacher e Herbart, à qual está na base de sua própria filosofia da educação. De Schleiermacher, Schmied-Kowarzik herda a análise dialética da práxis pensada no sentido hermenêutico, colocando-a como primado do agir educacional. Tal primado conduz à ideia de que desde sempre nos encontramos na práxis social da educação, permitindo a compreensão da educabilidade (Bildsamkeit) como condição propriamente humana. Por meio de tal compreensão, esboça-se uma dupla tarefa para a própria educação:

- trazer o educando para dentro da vida social e;

- nesta inserção, auxiliá-lo na construção de sua própria individualidade. Tais tarefas são levadas adiante pelo trabalho de mediação constante do educador.

Se Schleiermacher abre o horizonte da formação humana a partir da tradição dialética de inspiração platônica, Johann Herbart conduz Schmied-Kowarzik à filosofia prática kantiana e, com ela, à própria pedagogia. Decisivo, torna-se aí, em primeiro lugar, o fato de Immanuel Kant atribuir à formação (Bildung) a tarefa principal de provocar a maioridade nos envolvidos no processo educativo. Ou seja, Herbart, inspirado em Kant, pergunta pelo sentido formativo da pedagogia, concebendo-a na perspectiva de uma ciencia prática (praktische Wissenschaft). Em segundo lugar, como decorrência do aspecto anterior, Herbart distingue entre educação (Erziehung) e ensino (Unterricht). Enquanto a sistemática do ensino deve se ocupar com questóes relacionadas ao conteúdo e ao método, concentrando-se principalmente nos interesses dos alunos, a educação como formação precisa abrir um horizonte de ideias aos alunos. Encontra-se, aqui, em germe, a relação complementar entre ensino profissionalizante e educação para a vida (para o mundo), a qual será decisiva para a filosofia da educação desenvolvida por Schmied-Kowarzik já no contexto da sociedade alemã inteiramente industrializada. Contudo, por amparar-se na mais alta tradição alemã da Bildung, Wolfdietrich Schmied-Kowarzik não se deixa seduzir pelos apelos simplistas e imediatistas da formação para o mercado do trabalho e nem se engalfinhar pela mercantilização empresarial crescente da educação. Por isso, insiste, em sua produção intelectual voltada à filosofia da educaçáo, na 
ideia de que é indispensável a tarefa formativa da pedagogia no sentido de oferecer às novas geraçóes, aos adolecentes e jovens, uma orientação de mundo ${ }^{3}$.

Em síntese, encontramos na relação entre filosofia e educação pensada por Schmied-Kowarzik a influência de uma ampla tradição clássica, da qual fazem parte Schleiermacher e Herbart, como dois principais expoentes modernos. Disso, resulta uma dupla ideia para a filosofia da educação: primeiro, que a educabilidade humana precisa ser pensada no contexto da permanente tensão dialética entre indivíduo e sociedade; segundo, que cabe à pedagogia a tarefa eminentemente formativa, projetando-a para muito além do ensino profissionalizante, restrito ao domínio do saber especializado. Neste sentido, cabe à educação como formação (Erziehung als Bildung) a tarefa de descortinar o mundo às novas geraçôes. É este o pano de fundo teórico que conduz Schmied-Kowarzik a inserir a pedagogia no âmbito da filosofia prática (SCHMIED-KOWARZIK, 2003, p. 60-83).

O conteúdo resumido acima é apenas uma pequena amostra do rico repertório de ideias que o leitor encontrará na entrevista que o professor Wolfdietrich Schmied-Kowarzik gentilmente nos concedeu de Viena (Austria), onde reside atualmente.

\section{Entrevista}

Claudio A. Dalbosco: Professor Wolfdietrich Schmied-Kowarzik, o senhor poderia contar-nos algo acerca de alguns aspectos de sua biografia: como foram sua infância e seus estudos? Por que o senhor se decidiu pela Filosofia e pela ocupação com questóes educacionais? Quais foram suas mais importantes influências intelectuais?

W. Schmied-Kowarzik: Primeiro, eu gostaria de adiantar alguns dados biográficos. Eu vim ao mundo como filho mais novo de meus pais, em março de 1939, pouco antes do início da Segunda Guerra Mundial. Fui um retardatário, meus pais poderiam ter sido também meus avós. Meu pai, Prof. Dr. Walter Schmied-Kowarzik, tinha 54 anos, e minha mãe, a autora báltico-alemã Gertrud von Brincken, 47 anos quando de meu nascimento. Nos primeiros cinco anos, cresci em Mödling, próximo a Viena, na cidade de origem de meu pai. Nessa época, minha mãe estava na alta florescência de sua produção como autora de romances; ocupando-se, por isso, de mim, tias e amas, sobretudo. Meu irmão mais velho tinha 22 anos mais do que eu e estava servindo na guerra como oficial de artilharia; o próximo irmão era 10 e minha irmã cinco anos mais velhos.

Quando a armada soviética avançou sobre Viena, minha mãe fugiu conosco, os irmãos mais jovens, para o campo, na Bavária, onde nos alojamos na residência de uma tia, no castelo de Unterbruck. Em cada quarto dessa antiquíssima construção do século XII, morava uma família de fugitivos. Quando meu pai 
veio até nós, após um ano de prisão, passamos a viver os cinco juntos nesse espaço escuro e úmido, que era cozinha, sala de estar e dormitório em um só. Nesse tempo de pós-guerra, foi minha mãe quem cuidou do sustento da família ministrando aulas de inglês, pois meu pai só voltou a ganhar seus vencimentos de pensão a partir dos anos 1950. Eu mesmo pouco percebi da tais preocupaçóes e necessidades. Na aldeia vizinha, junto com outros filhos de camponeses e fugitivos, nós frequentávamos em uma só classe a Escola primária e auxiliávamos nos campos em períodos de colheita. Brincávamos também nos celeiros ou colhíamos frutos silvestres e cogumelos na mata vivendo, enfim, a vida campesina. Eu não era um bom aluno — hoje se falaria de dislexia — , ficava também seguidamente doente (infecção pulmonar e problemas cardíacos), de modo que fracassei lastimavelmente, quando da primeira tentativa de ser aceito em um Ginásio.

Em 1950, com grandes sacrifícios, meus pais conseguiram mudar-se para o distrito de Regensburg, onde eu então ingressei no Ginásio e, em 1959, prestei o exame final do Segundo Grau. Nos primeiros anos, fui um aluno muito ruim, que só com muito esforço avançava de ano a ano. Meu irmão mais velho, que entretempos se tornara um bem sucedido agente de patentes, e o outro, que se iniciava como escritor e historiador de arte, consolaram meus preocupados pais, dizendo que eu poderia tornar-me, talvez, um dia, um hábil trabalhador manual. $\mathrm{O}$ que, confesso, me feriu o orgulho. Justamente naquela altura, nossa classe ganhava um novo professor de Matemática e Física, o qual havia tido também, ele mesmo, grande dificuldade de passar nas provas de admissão ao ensino público. Diferentemente de todos os outros professores, ele não se punha a nossa frente de modo ostensivo; era antes inibido e tímido, mas sabia como nos entusiasmar. Tornei-me, assim, um aluno de sucesso primeiro nessas disciplinas, e, então, nos últimos anos, em todas as matérias; com excessão, infelizmente — devido à minha dislexia —, das disciplinas de línguas.

Assim, em 1959, me inscrevi na Universidade de Viena, para o estudo de Filosofia e Astronomia. Embora meu pai tivesse sido professor de Filosofia e Psicologia, só comecei a me interessar por Filosofia na Escola, a partir da penúltima classe. Como ele, entretanto, veio a morrer naquele mesmo ano, de 1958, chegamos a ter muito poucas conversas filosóficas. Meu interesse, contudo, não diminuiu, e quando o professor de Física, em Viena, quis dissuadir-me do estudo de Filosofia, já um semestre após, desisti do estudo de Física e Matemática, passando a frequentar, além da Filosofia, também Etnologia e alguma coisa de Psicologia. Pedagogia eu jamais estudei.

$\mathrm{Na}$ Filosofia, eu, na verdade, frequentei as aulas de todos os três professores, tal como dos livre-docentes, tendo sido marcado, entretanto, especialmente pelo hegeliano Erich Heintel, que me orientou também na elaboração de minha Dissertação, Sentido e Existência na Filosofia tardia de Schelling. Igualmente intensivo, porém, foi meu estudo de Etnologia, com um leque de 
aulas fundamentais, científico-culturais, acerca da pré-história, da antropologia, japanologia e egiptologia.

Claudio A. Dalbosco: Durante os anos 60 do último século, o senhor escreveu seu trabalho de Livre-docência sob orientação do Prof. Dr. Josef Derbolav, na Universidade de Bonn. Poderia dizer-nos algo acerca do significado desta experiência intelectual para sua formação filosófica e pedagógica? $\mathrm{O}$ que foi marcante para o senhor?

W. Schmied-Kowarzik: Logo após o doutorado, em dezembro de 1963, ocupei, junto a Josef Derbolav — que era austríaco e havia assumido de seu amigo de estudos, Erich Heintel, todos os seus Assistentes de trabalho -, uma vaga de Assistente no Instituto de Ciência da Educação, na Universidade de Bonn. Minhas preocupaçóes quanto a que não pudesse ter aptidão para essa tarefa eram infundadas, pois Derbolav ocupava a Cadeira de Filosofia e Pedagogia, fundada por Theodor Litt, defendendo uma teoria da formação orientada fortemente em Hegel. Neste contexto intelectual, não tive dificuldade de me familiarizar com questóes sistemáticas da formação (Bildung) e educação (Erziehung), tendo como pano de fundo a Filosofia.

Um ano depois, Dietrich Benner ${ }^{4}$, que havia feito seu doutorado também sob orientação de Heintel, pôde ser trazido como Assistente à Universidade de Bonn. Juntos nós formamos - embora ainda muito jovens - um forte time. A partir de leituras dos clássicos da Pedagogia, de Platão e Aristóteles, passando por Johann Amos Comenius e Jean-Jacques Rousseau, assim como por Herbart e Schleiermacher até a teoria da formação do século XX, nós começamos a elaborar um esboço próprio de Pedagogia enquanto disciplina prática, ao qual demos o título exigente de Prolegômena à Fundamentação da Pedagogia, que deveria aparecer em três volumes. Dois volumes referentes à Filosofia e Pedagogia prática de Herbart já haviam saído, e tínhamos iniciado a trabalhar no terceiro volume referente à Doutrina Pedagógica de Schleiermacher, quando a revolta estudantil atingiu a Universidade. Como se discutia a supressão da Livre-docência, os professores pressionaram seus Assistentes a defenderem sua livre-docência, tão logo que possível. Benner e eu apresentamos os nossos dois volumes e fomos ambos habilitados em um e mesmo dia daquele verâo de 1970.

Como, logo depois, nós dois recebemos ofertas de vagas como professores substitutos - Benner em Freiburg e eu em Münster —, nunca pudemos concluir o terceiro volume. Cada um de nós, porém, dedicou uma publicaçáo própria de nosso plano sistemático comum: Dietrich Benner escreveu a obra Correntes principais da Ciência da Educação (BENNER, 1978) e eu, Pedagogia Dialética (1974), posteriormente publicada em português pela Editora Brasiliense (SCHMIED-KOWARZIK, 1983). Embora nosso caminho acadêmico nos separasse - Benner tornou-se professor de Pedagogia Sistemática primeiro em Münster e depois em Berlim, eu fui chamado para a cátedra de Filosofia e Pe- 
dagogia na então recém-fundada Escola Superior Integrada de Kassel —, nós, entretanto, permanecemos ligados no ponto de partida de nosso pensamento. Ambos, Benner e eu, fazemos uma diferença entre uma teoria da educação (Erziehungstheorie) voltada à ação, na qual se trata principalmente da relação entre educador e educando, professor e aluno, e uma teoria da formação (Bildunstheorie), na qual estão em questão os horizontes de mundo que devem ser abertos ao jovem educando. Ambas as questóes serão abordadas por uma autoclarificação fundamental-filosófica da Pedagogia como ciência prática. É preciso considerar, neste contexto, que, para a Pedagogia, em todas as suas formulações de problemas não se trata de depoimentos cognitivos afirmativos, senão de abrir perspectivas de ação e objetivos para o educador ou professor ${ }^{5}$.

Em Bonn, também conheci Iris von Gottberg, que aí estudou na Escola Superior de Pedagogia e concluiu sua Licenciatura com um trabalho sobre a Pedagogia de Herbart. Casamo-nos em 1966 e temos, juntos, três filhos, que nesse meio tempo se doutoraram e seguem com sucesso o seu caminho profissional.

Claudio A. Dalbosco: Após sua Livre-Docência, o senhor assumiu um professorado na cadeira de Filosofia prática e Pedagogia, na Escola Superior Integrada de Kassel, convivendo profissionalmente com Ulrich Sonnemann, amigo pessoal de Theodor W. Adorno. O senhor trabalhou, também, com outros professores em uma forma muito especial de trabalho científico conjunto, que se desenvolveu dentro do - fundado em 1978, também por sua iniciativa — Grupo de Trabalho Interdisciplinar para Problemas de Fundamentação Filosófica da Ciência e da Práxis Social (IAG), naquela Universidade. Quais foram as experiências ligadas a esse trabalho e em que sentido o senhor conceberia ainda como atual, para a Universidade, esse trabalho interdisciplinar?

W. Schmied-Kowazik: Deve-se agradecer à fundação precipitada da Escola Superior Integrada de Kassel, a sua orientação interdisciplinar. Orientação esta que seria dificilmente transmissível a uma outra Universidade já existente. Somente quando de minha segunda estadia no Brasil, em 1999, vivi situaçóes semelhantes de arrancada interdisciplinar em Universidades recém-fundadas e marcadas por experiências comunitárias e regionais, sobretudo no Sul do Brasil.

A ideia da Escola Superior Integrada de Kassel era a de reunir em um estudo fundamental em comum todas as áreas do Ensino Superior e, antes de tudo, as direçóes de estudos mais fortemente teoréticos, dando-lhes também um sentido prático. Levar, por exemplo, os engenheiros e engenheiros diplomados a um núcleo conjunto de estudos, a fim de então conduzi-los a uma conclusão mais curta ou mais longa, como engenheiro ou engenheiro diplomado. De modo semelhante, todos os professores da Escola Fundamental até o nível mais elevado, desde a Realschule (dez anos de escolaridade) até o Ginásio (mais três anos de escolaridade), deveriam experimentar um núcleo de formação pedagógica comum, o qual somente mais tarde deveria diferenciar-se segundo o nível ou os tipos de Escolas 
frequentadas. Esse planejamento pressupunha que todas as Escolas Superiores já existentes fossem incluídas juntas na nova fundação. Aos novos professores chamados a trabalhar nos ramos universitários recém-formados, competia a tarefa de configurar a unidade e as diferenciaçóes do novo complexo e, enquanto Escola Superior Integrada, projetar novos cursos e iniciar simultaneamente o período letivo, com os novos estudantes inscritos.

Por um lado, essa carência de planejamentos preparatórios administrativos e acadêmicos era uma inacreditável carga de exigências para os professores; por outro, contudo, tal desafio desencadeou, em nós, uma grande criatividade no trabalho interdisciplinar conjunto, o que seria impensável em uma Universidade tradicional, com suas estruturas já batidas. Felizmente, em Kassel, entre as Escolas Superiores já existentes e voltadas à prática — a da Engenharia, da Economia, da Agrologia, tal como um Instituto Pedagógico - , e o novo ramo universitário a fundar, ainda existia a antiga e venerável Escola Superior de Arte. Esta, com suas cátedras de Arte Livre, mas também de Filosofia da Arte, História da Arte, Sociologia da Arte e Psicologia da Arte, revelou-se uma ponte fecunda, sem a qual se teria chegado, no início, a tensões ainda maiores ${ }^{6}$.

Os novos professores concursados - da Matemática e das Ciências Naturais, da Literatura e Letras, tal como da Educação e Ciências Sociais - haviam sido chamados exclusivamente para a construção de uma Formação Integrativa de Professores Escolares. Ainda assim, eles buscavam também construir suas próprias disciplinas, de tal modo que essas mais tarde possibilitassem currículos independentes de Diplomação e de Mestrado. De fato, isso depois surtiu efeito, em 1984, para todas as disciplinas, desde a Matemática até a Ciência da História e, respectivamente, desde a Física até a Filosofia.

Eu mesmo fui chamado a assumir, nesse contexto, primeiro, apenas a vaga de Filosofia da Educação no quadro da Educação de Professores da Escola. Foi quando, juntamente com os filósofos da arte da antiga Escola Superior de Arte e muitos outros colegas filosoficamente orientados, da Sociologia, Psicanálise, Política e Ciência da Educação, chegamos a formar um círculo de interessados, conseguindo que se contratasse mais um filósofo. De modo bem consciente, chamamos Ulrich Sonnemann para essa terceira cátedra de Filosofia, já que ele pertencendo à Teoria Crítica — tinha também a apresentar trabalhos de Psicologia Social e Crítica da Sociedade, estando assim aberto para uma concepção interdisciplinar de Filosofia. Ulrich Sonnemann já estava com 61 anos de idade quando foi chamado a Kassel, mas, nos 18 anos em que ainda lecionou, trouxe um espírito crítico tão grande e jovem à discussão, que emprestou asas a todos nós.

O motivo para a fundação do Grupo de Trabalho Interdisciplinar para Problemas Filosóficos de Base (IAG Philosophie), que existiu de 1978 até 2006, foi triplo: por um lado, importava reunir aqueles que, vindos de diversos domínios científicos, interessavam-se também por questôes filosóficas. Por outro, fortalecer 
as reflexóes filosóficas nas diversas disciplinas e provocar disputas críticas sobre as ciências. Por fim, cultivar, na jovem Escola Superior Integrada de Kassel, através de palestras de convidados e colóquios temáticos, um clima de discussão filosófica ${ }^{7}$. Memorável foi o nosso primeiro círculo de discussão sobre o problema do tempo, que durou alguns anos e do qual participaram professores das mais variadas disciplinas, desde um físico, passando por um psicanalista, até alguns colegas da Educação e das Ciências Sociais — e, naturalmente, alguns estudantes. Notáveis foram também as disputas científicas das mais diversas disciplinas, tais como entre cientistas políticos e historiadores, ou a controvérsia científica entre o economista Hans Immler e eu, que foi publicada em livro, em 1984, com edição ampliada em 2011, sob o título: Marx und die Naturfrage. Ein Wissenschaftsstreit um die "Kritik der politischen Ökonomie" (Marx e a Questão da Natureza. Uma controvérsia científica em torno à "Crítica da Economia Política — IMMLER, SCHMIED-KOWARZIK, 2011).

Dos grandes Colóquios e Congressos, quero mencionar apenas o primeiro Congresso Internacional Rosenzweig pelos 100 anos de nascimento do filósofo da Religião, natural de Kassel, o judeu Franz Rosenzweig, realizado em 1986. Para o Congresso, vieram 70 palestrantes de todo mundo, entre eles alguns que haviam trabalhado com Rosenzweig ainda na década de 1920. Devido ao Congresso-Rosenzweig, uma série deles - que um dia haviam iniciado na Alemanha sua carreira acadêmica e sido entáo impelidos à emigração — , voltou, pela primeira vez, a pisar o solo alemão. Por causa dessa experiência, criamos a cátedra "Franz Rosenzweig para Professores Convidados"; nesta, filósofos ou representantes das Ciências Humanas expulsos um dia da Europa para o exílio pelo Nacionalsocialismo, podem, desde 1987, dar cursos durante todo um semestre de verão. Palestras e notícias autobiográficas dos primeiros 20 professores convidados, eu as publiquei em dois livros: Vergegenwärtigung des zerstörten jüdischen Erbes (Presentificação da Herança judaica destruída — SCHMIED-KOWARZIK, 1997) e und Auseinandersetzung mit dem zerstörten jüdischen Erbe (Disputas em torno à Herança judaica destruída — SCHMIED-KOWARZIK, 2004). No segundo Congresso Internacional Rosenzweig, ocorrido em 2004, em Kassel (Franz Rosenzweigs neues Denken, 2 Bde ou O novo pensamento de Franz Rosenzweig, 2 vol, - SCHMIED-KOWARZIK, 2006), evidenciou-se em que solo frutífero havia caído a nossa iniciativa. Pois, neste mesmo Congresso, pudemos fundar a Sociedade Internacional-Rosenzweig, a qual, já nos primeiros 10 anos de sua existência, levou à realização de consideráveis cooperaçóes internacionais de pesquisa sobre o tema.

Claudio A. Dalbosco: Sua posição intelectual deixa perceber que Friedrich Schelling seria o filósofo de seu coração. Por que o senhor o considera tão importante? Em que consiste a contribuição de Schelling para seu próprio caminho filosófico? 
W. Schmied-Kowarzik: Está correto; a preocupação com Schelling me acompanha desde os primeiros anos de estudos. Minha tese final (Doutorado) ocupa-se com o tema Sinn und Existenz in der Spätphilosophie Schellings (Sentido e Existência na Filosofia tardia de Schelling - SCHMIED-KOWARZIK, 1963), e acabo de finalizar um livro, Existenz denken, 2015 (Pensar a Existência, 2015), que discute com A Filosofia de Schelling desde os primeiros inícios até a Obra tardia (SCHMIED-KOWARZIK, 2015). Minha afinidade com Schelling nasce de uma preocupação filosófica fundamental. Em Viena, quando iniciei meus estudos de filosofia, caí na escola hegeliana de Erich Heintel. Quase todos os meus colegas tomaram a si temas da filosofia hegeliana. Eu, ao contrário, encarei o Idealismo absoluto de Hegel com ceticismo. O pensamento ou o espírito abarca realmente a si mesmo e ao outro, ao ser? Pois, a existência afinal não é de modo algum um predicado, como já o sublinhou Kant, senão a "posição absoluta", à qual se refere toda predicação do pensamento. Em Schelling, eu encontrei um pensador que perseguiu, desde o início, esta questáo. A unidade de pensar e ser que somos nós, quando dizemos "eu sou", é a unidade de dois momentos diversos, da autocerteza e da certeza da existência. Neste sentido, Schelling fala do ser humano como "problema visível, vagabundeando através de toda a filosofia” (SCHELLING, 1995, II, p. 54). Na sua filosofia tardia, na qual Schelling então se distanciou decididamente do Idealismo absoluto de Hegel, ele se torna ainda mais claro e fala da "imprépensabilidade da existência" (Unvordenklichkeit der Existenz), na qual, metidos dentro dela, nós precisamos experimentar. E ele interpreta isso de modo filosófico-religioso, enquanto o caminho "da consciência que póe necessariamente Deus" ao longo da história humana. Tal caminho seria uma libertação do espírito humano, sem que, entretanto, essa consciência que póe Deus, como Schelling sublinha contra Hegel, possa jamais pretender tornar-se Deus, ela mesma.

Devido a isso, Schelling pôde construir uma compreensão inteiramente outra da produtividade autossuficiente da natureza, na qual nós, homens, estamos incluídos e a qual temos também de preservar com responsabilidade. Contudo, eu reconheci também, muitos anos mais tarde, que o ponto de partida de Schelling representa a verdadeira fundamentação filosófica para a dialética materialista da história, de Karl Marx. Sim, que, na sua própria crítica a Hegel, em seus escritos filosóficos, Marx chega bem próximo à crítica de Schelling a Hegel. Os meus estudos a esse respeito, que se estendem ao longo de quarenta anos, eu os reuni recentemente no livro Hegel in der Kritik zwischen Schelling und Marx, 2014 (Hegel na Critica entre Schelling e Marx - SCHMIED-KOWARZIK, 2014). Eu aí não quero dizer que Hegel, enquanto filósofo, seria jamais superado; sua Fenomenologia do Espirito, assim como sua Ciência da Lógica e sua Filosofia do Direito permanecerão sempre uma fonte de inspiração. Porém, no que tange às nossas tarefas para com a humanidade, seremos muito mais fundamentalmente conduzidos à natureza e à história por Schelling e Marx. 
Claudio A. Dalbosco: Um interesse de seu versátil e amplo caminho intelectual sempre foi a relação entre Filosofia e Educação. Nesse contexto, o senhor se interessou especialmente por Johann Friedrich Herbart e Friedrich Schleiermacher.

- Em que medida o senhor considera ainda relevante a Pedagogia científica de Herbart?

- Em que sentido a Hermenêutica de Schleiermacher é ainda importante para se pensar Filosofia e Educação?

- Qual seria a ideia central da Filosofia da Educação em ambos os autores?

W. Schmied-Kowarzik: No início do século XIX, com Herbart e Schleiermacher, a Pedagogia ganha a sua independência como ciência fundamentada filosoficamente. Há, naturalmente, grandes precursores - sem considerar Sócrates e Platão —, sobretudo Johann Amos Comenius e Jean-Jacques Rousseau, como teóricos da formação e educação. Mas os primeiros a elevar a Pedagogia a uma ciência autônoma foram Schleiermacher e Herbart, sendo nisto até hoje determinantes, ainda que de modo diferente.

Schleiermacher, o grande teólogo e filósofo protestante, apresentou sua Leitura sobre Pedagogia (SCHLEIERMACHER, 2000), no contexto de seus cursos na Universidade de Berlim. Esses cursos chegaram a nós, infelizmente, apenas como anotaçôes de aulas de seus alunos, razáo esta por que não são facilmente acessíveis. É preciso que se recorra à ajuda de sua Dialética e de suas preleçôes sobre Ética, para poder decifrar inteiramente a incrível riqueza de sua Doutrina da Educação e de suas ideias sobre o sistema educativo. De resto, o que marca a Pedagogia de Schleiermacher não é a sua hermenêutica, senão sua análise dialética da práxis no primado do agir educacional. Wilhelm Dilthey foi o primeiro a ampliar a hermenêutica de Schleiermacher para a práxis social global, de modo que sua hermenêutica pôde tornar-se relevante também para a Pedagogia. Com isso, no entanto, a Pedagogia de Schleiermaher dialeticamente concebida como práxis filosófica, viu-se fortemente reduzida. Eis porquê, no que diz respeito às ciências práticas da Pedagogia e da Política, eu defendo uma volta justamente à dialética de Schleiermacher. Pois, afinal, sua hermenêutica é ela mesma dialeticamente fundamentada e não ao inverso.

Nós conhecemos Schleiermacher também como o incomparável tradutor dos Diálogos de Platão para o alemão, mas ele é ao fundo inspirado pelo método propagado por Aristóteles de busca do meio termo. O cerne de seu pensamento é o seguinte: nós estamos já sempre no centro da práxis social da Educação. Não temos dela nenhuma pré-definição vinda de fora, daí que haja uma só possibilidade de esclarecer dialeticamente a práxis na qual figuramos já sempre, para, mediante isso, ganharmos orientação dialética para nossa práxis de ação consciente. $\mathrm{O}$ arco mais fundamental de tensão dialética é aquele entre o 
indivíduo e a sociedade, pois não pode haver indivíduo algum sem sociedade, sendo que o inverso também é válido. De modo que compete à educação uma dupla tarefa: trazer cada recém nascido humano para dentro da comunidade da vida social, na qual ele precisa afirmar-se; ao mesmo tempo, trazer também cada ser nascido para dentro de um determinado ambiente social, visando construir sua própria individualidade.

Esse primeiro arco de tensão será atravessado por um segundo, ortogonal: pelo aí já dado e pelo que se objetiva alcançar. Por toda parte em que entremos em uma práxis, nós topamos com uma dada situação tanto no que se refere a crianças e jovens quanto também no que diz respeito às relaçóes sociais. Deste modo, temos a tarefa pedagógica de realizar, mediante nossa práxis educacional, algo com vistas ao futuro da juventude assim como da sociedade. Em um outro cruzamento ortogonal — que em Schleiermacher é decerto infinitamente mais diferenciado e de fina tecitura do que me é possível apresentar aqui —, ele reflete ainda também a relação teoria-práxis da Pedagogia enquanto ciência. Mais precisamente, a Pedagogia é, segundo ele, uma ciência prática, pois ela é esclarecimento teorético de uma praxis existente, para esclarecimento prático dos agentes pedagógicos ${ }^{8}$.

Herbart não se pergunta, como Schleiermacher, a partir da perspectiva do agente educacional; ele pergunta pela essência da tarefa da formação na Pedagogia. Metida em uma vida moral em comum dos seres humanos em sociedade, a mais elevada tarefa da Formação é, para ele, conduzir o adolescente à maioridade, a fim de este - como diz Herbart — poder realizar sua "vida adulta" de modo moral-prático. Para poder alcançar isso o adolescente precisa, por um lado, mediante determinados conteúdos educativos, adquirir um "horizonte de ideias" e, por outro lado, certa "força de caráter". A partir disso, Herbart desenvolve então a sua sistemática para um "Ensino educativo". Infelizmente, aconteceu de já os seus sucessores imediatos não mais entenderem essa sistemática do ensino como um olhar fenomenológico para o conteúdo do ensino e para a mediatização de atitudes, senáo como um esquematismo para o decurso do ensino entendido de modo rígido. Com isso, a Pedagogia herbartiana tornou-se a suma da formação educacional rigorosamente formalista, a qual só foi quebrada mediante o movimento reformista do início do século XX.

Com essa estigmatização comete-se, no entanto, injustiça para com a intenção de Herbart, que ambicionava francamente o oposto a qualquer formalismo. Pois era abrir o olhar ao essencial do ensino o que ele intencionava. $\mathrm{Na}$ formação, ele acentuava expressamente que não se trata de um saber pelo saber, mas sim de despertar "interesses" por um objeto - por exemplo, pela investigação da natureza - e provocar a "participaçâo" interior por um acontecimento - por exemplo, no ensino de história ou de literatura. Herbart também refletia sobre a relação teoria-práxis da Pedagogia enquanto ciência, só que não mais como Schleiermacher, que a referia imediatamente ao agir educacional, 
senão ao "horizonte" do pedagogo. Isto é, a Pedagogia não deveria fixar o futuro educador mediante saberes e regras, senáo abrir-lhe um horizonte, um olhar para o essencial da Formação, para que este pudesse configurar autonomamente o seu fazer pedagógico.

Schleiermacher e Herbart apontaram, cada um deles, a um aspecto do que a Pedagogia tem a realizar. Não deveríamos jogá-los um contra o outro, mas antes acentuar que ambas as concepçóes são necessárias para vencer toda amplitude do questionamento pedagógico. Seja lá onde for que se trate do verdadeiramente pedagógico, as intervençóes até hoje derivam, consciente ou inconscientemente, dessas duas perspectivas.

Claudio A. Dalbosco: Seu projeto central de pesquisa é sobre Filosofia e Práxis Social. No âmbito desse projeto, o senhor argumenta pelo primado da razão prática, originando-a basicamente de dois grandes troncos: da filosofia antiga (Platão) e da filosofia moderna (Marx).

- O que significa propriamente o primado da razão prática?

- Em que sentido o senhor considera decisivo tal primado para pensar a relação entre Filosofia e Educação?

- Que papel tem Karl Marx em sua fundamentação da Filosofia e Práxis social? Em que sentido são ainda atuais as ideias de Marx?

W. Schmied-Kowarzik: Com Platão, a filosofia toda ainda estava sob o primado da práxis, sob o que é entendida sempre a práxis moral. Pense-se apenas nos primeiros diálogos socráticos. Eles giram principalmente em torno à questão de o que seria a virtude, sendo que náo se trata, aí, de um saber sobre a virtude, mas de encontrar insights e atitudes virtuosos. No diálogo Euthydemos essa diferença encontra-se expressamente tematizada. Também o Platão mais velho expóe, na Politeia, que os filósofos deveriam pôr-se primeiro a serviço da pólis e entregar-se ao pensamento só na idade avançada. Esse primado vê-se depois invertido, com Aristóteles. Para este, a filosofia teórica torna-se a "ciência primeira", sendo que a filosofia prática (Ética, Política, Pedagogia) ganha um significado apenas secundário. Isso acontece porque a "filosofia primeira" consegue chegar a afirmaçôes apodíticas, enquanto a filosofia prática refere-se já sempre a uma práxis anterior, conseguindo chegar apenas a suposiçóes e conselhos muito vagos.

A grande corrente da filosofia ocidental seguiu Aristóteles. Kant foi o primeiro a declarar-se decididamente a favor do primado da razão prática, mostrando, exatamente ao contrário de Aristóteles, que as ciências, mesmo chegando a determinadas afirmaçóes, jamais podem alcançar a realidade em si. Contudo, a razão prática, embora não conseguindo apresentar quaisquer afirmaçôes de conhecimento, afetaria com determinação (moral) a realidade em si. De mais a mais, com Kant, vê-se também sublinhado — como já com Platáo —, que nas disci- 
plinas práticas da Ética, Pedagogia e Política não se trata de um conhecimento melhor da práxis e também não de instruçôes apodíticas de produção técnica. Trata-se mais bem de uma forma de certeza que Kant nomeia "imperativo categórico", e a que podemos circunscrever como "consciência moral".

O próprio Kant já havia transcrito, nas suas Preleçóes Sobre a Pedagogia (2002) e em seus escritos político-históricos, o fundamental de sua Crítica da Razão Pura com vistas à Educação e à Política. Johann Gottlieb Fichte foi ainda mais claro acerca disso, no seu Fundamento do Direito Natural (FICHTE, 1997) e em seus escritos políticos. Contudo, só os primeiros fichteanos do início do século XIX e, mais tarde, os neokantianos do início do século XX levaram ao fim a discussáo filosófica fundamental referida antes de tudo à Pedagogia. Todos os problemas são-nos já conhecidos através de Platão, tornando-se agora, entretanto, outra vez, mais fundamentalmente evidentes para o pensar e o agir pedagógicos. Com os fichteanos tudo gira em torno ao problema básico da Educação, ao qual Fichte circunscreve como Exortação à autoatividade. Com essa formulação paradoxal, a problemática fundamental - de como o educador pode conduzir o aluno desde o berço até a idade adulta, de degrau em degrau, até a sua livre autodeterminação (Emílio de Rousseau) — vê-se apanhada duplamente? . De um lado, verdadeiros juízos e uma consciência moral forte são construídos apenas pelo próprio educando (Anamnésis de Platâo); de outro lado, precisa-se, para isso, do estímulo do educador (Maiêutica de Platáo). Em contrapartida a isso, os neokantianos discutem mais o problema da Formaçáo: perguntam-se sobre os horizontes de mundo e as reivindicaçóes sociais mais adequadas a sua idade, que devem ser abertas aos jovens, a fim de que, na práxis social, eles possam comportar-se como adultos autônomos em relação a isso. Também aqui trata-se de uma problematização paradoxal, a qual o neokantiano Jonas Cohn circunscreveu em sua obra Befreien und Binden (Libertar e Ligar - COHN, 1927).

Todas essas considerações não são solúveis nem pelo saber cognitivo, nem mediante técnicas. Isso não quer dizer que conhecimento empírico-psicológico e sociológico, tal como habilidade metódica e didática careceriam de significado para a Pedagogia. Eles, contudo, serão sempre para ela apenas meios auxiliares, porque não fazem jus nem substituem insights pedagógicos fundamentais.

Em certo paralelo à Pedagogia enquanto ciência prática, isto é, em última instância sempre enquanto ciência moral prática, deve-se entender também a Política como guia de uma sociedade através da história. Com respeito a isso, Karl Marx é um dos mais importantes filósofos da práxis nos tempos modernos. Já em seus primeiros escritos filosóficos ele tornou claro, frente a Hegel, que a filosofia não pode encontrar seu cumprimento em conhecer e conceber, mas que a análise crítica que ela faz da práxis existente intervém sempre de modo também transformador nessa práxis, na medida em que esclarece os indivíduos agentes acerca de sua situação de vida e os leva, com isso, à consciência do que eles têm 
a realizar em comum. Nesse ponto, a filosofia crítica encontra-se ela mesma no primado da práxis ou, como diz Marx, ela se entende como tomando partido pela "emancipação humana". Sob essa pretensão prática compreende-se também a sua gigantesca e nunca concluída obra tardia, Crítica da Economia política, a qual não deve ser mal-entendida como uma mera ciência econômica, da qual se poderia deduzir propostas de melhorias econômicas. Ao contrário disso, Marx quer mostrar fundamentalmente que a economia capitalista dominante nega, em princípio, a vida humana comunitária e a própria natureza enquanto base primordial da vida, destruindo-as. De modo que, para os seres humanos afetados por esta situação torna-se clara a necessidade de superar a economia capitalista em nome de um futuro solidário e ecológico.

Eu acredito que, frente aos problemas ecológicos de sobrevivência, no século XXI, viveremos certo renascimento da filosofia de Marx. Um renascimento, no qual não se trata de apenas reproduzir Marx servilmente, mas de seguir desenvolvendo, a partir de seu espírito, uma filosofia prática que se disponha a assumir tarefas referentes à história da humanidade, de desenvolver adiante a sua crítica, como no século XX já o empreenderam Georg Lukács, Antonio Gramsci, Ernst Bloch, Herbert Marcuse, Henri Lefèbvre, entre outros.

Claudio A. Dalbosco: O diálogo crítico com a tradição alemã da Bildung foi-lhe sempre importante. O senhor tem tal tradição ainda por relevante? Em que sentido o conceito clássico de Formação (Bildung) deveria ser atualizado?

W. Schmied-Kowarzik: Com olhar retrospectivo sobre a filosofia grega, Herbart e Schleiermacher — com suas Preleçóes sobre Pedagogia —, lançaram a pedra fundadora para um debate filosófico fundamental sobre a Formação e a Educação. Seus estímulos, levados adiante de modo inteiramente crítico, entraram nas correntes pedagógicas do século XX. No espaço da língua alemã, quase todas as cátedras do ensino de Pedagogia resultaram da Filosofia, de modo que, até os anos 70 do século XX ainda existia, na discussão de base da Pedagogia, uma estreita ligação com a Filosofia. Existiam várias escolas de Pedagogia Sistemática, a saber: a Pedagogia das Ciências do Espírito, da tradição de Wilhelm Dilthey, que se reportava de modo especialmente forte a Schleiermacher; a Pedagogia do neokantianismo, na qual eu gostaria de salientar sobretudo Richard Hönigswald; uma Pedagogia da filosofia da existência, que se apoiava em Martin Heidegger, com Eugen Fink como o pensador mais marcante; a Filosofia da Educação, de Theodor Litt e Josef Derbolav, que se sabe especialmente devedora a Hegel; e, finalmente, a Pedagogia crítica da Sociedade, que foi representada de modo marcante por Joachim Heydorn. O mais fecundo nessa multiplicidade de abordagens não era a delimitaçáo e o isolamento que se podia apontar entre umas e outras, mas, sim, a discussão séria entre todas, travada na frente dos estudantes, abrindo-lhes, deste modo, uma perspectiva diferenciada de seu fazer pedagógico, com vistas a sua formação humana e profissional. 
Essa tradição viu-se de modo abrupto interrompida a partir dos anos 1970, quando as cátedras de Filosofia e Pedagogia não foram mais ocupadas, e mesmo a Pedagogia Sistemática viu-se dividida em disciplinas especiais. Repetia-se, aqui, um movimento de separação em relação à Filosofia, o qual se havia consumado antes na Psicologia (nos anos 1920) e na Sociologia (nos anos 1960). Com tal separação, o ensino acadêmico nessas disciplinas passou a concentrar-se mais e mais em uma mediação do conhecimento que só serve à aplicação técnica, perdendo-se assim de modo crescente a ideia originária de Bildung (Formação). A bem da verdade, é preciso naturalmente acrescentar que um movimento similar consumou-se também no espaço da língua alemã em relação à Filosofia, à época, quando a tradição filosófica clássica viu-se desalojada pela Filosofia Analítica. Quero dizer, com isso, que, para questóes básicas da Educação, pouco restava a experimentar para a Pedagogia no que se refere a clarificaçóes vindas da Filosofia Analítica defendida nas Universidades.

É difícil dizer como se poderia ter agido contra isso, pois esses movimentos afinal correspondiam à tendência vinda da sociedade como um todo, isto é, aquela da economização do sistema educacional. O input financeiro dos recursos estatais deve corresponder o mais possível ao output de profissionais qualificados e prontos a trabalhar no mercado e na administração, de modo a que os mesmos (recursos) retornem, mediante impostos, às Caixas do Estado. Desse ponto de vista, o ensino tanto na Escola como na Universidade é orientado não à maioridade e à formação, mas à qualificação otimizada de professores. Neste caso, um pensamento demasiado crítico mostra-se apenas como potencial de estorvo, tendo de ser mantido fora da Escola e da Universidade.

Claudio A. Dalbosco: Seu livro Dialektische Pädagogik. Vom Bezug der Erziehungswissenschaft zur Praxis (SCHMIED-KOWARZIK, 1974), foi publicado em português em 1983, com segunda edição em 1988, sob o título: Pedagogia Dialética. De Aristóteles a Paulo Freire. Desde então, o livro influencia vários setores da pesquisa educacional brasileira.

- O que pensa o senhor, hoje, acerca da Pedagogia enquanto ciência prática da Educação e para a Educação?

- Em que medida é possível justificar a ideia da Pedagogia como ciência prática, evitando simultaneamente, o risco do positivismo?

W. Schmied-Kowarzik: Já para a tradução portuguesa, no início dos anos 1980, eu revisei e sistematizei exaustivamente o meu livro Dialética Pedagógica (SCHMIED-KOWARZIK, 1974). Minha tentativa de publicar novamente também na Alemanha esse texto mais rigoroso fracassou porque nos anos 1980 e 1990 nenhuma Editora estava disposta a publicar tal discussão de fundamentos. Revisei, afinal, mais uma vez o referido livro e o publiquei, novamente, em 2008, sob o título Dialektische Pädagogik. Vom Bezug der Erziehungswissenschaft 
zur Praxis (Pedagogia Dialética. Da relação da ciência da educação com a práxis) - SCHMIED-KOWARZIK, 1974), na série editada por Heinz Eidam e mim, "Kasseler Philosophische Schriften - Neue Folge." (Escritos Filosóficos de Kassel Novas Versōes).

Tal como antes, estou convicto de que a Pedagogia não é de modo algum uma ciência do conhecimento, cujo saber teria que ser aplicado em uma práxis técnica. Daí que eu também não goste de falar de uma Ciência da Educação. A Pedagogia, como a Ética e a Política, é uma ciência prática, que Aristóteles caracterizou acertadamente na Ética a Nicômacos — ainda que também pragmaticamente abreviada - enquanto disciplina que clarifica teoricamente uma práxis ética já acontecida antes, a fim de, deste modo, esclarecer os agentes pedagógicos em relação à práxis que lhes é dada como tarefa ${ }^{10}$.

A perspectiva alvo de uma tal ciência prática não é saber nenhum de fatos, senão a inteligência dos agentes, pedagogos ou políticos, para poderem decidir-se com consciência de responsabilidade, em termos pedagógicos ou políticos, frente a cada nova situação e cada novo indivíduo.

Só quando a Pedagogia vier a compreender-se deste modo, isto é, enquanto sendo não uma ciência constatadora ou tecnicamente condutora, senáo moral-prática, ela produzirá pedagogos com competência de ação, eles mesmos capazes de deixar crianças e jovens tornarem-se, por sua vez, adultos competentes de ação. A especial competência de ação dos pedagogos precisa ser formada numa dupla direção: por um lado, frente à pressão estatal e econômica da sociedade. Eles têm de poder transformar criticamente, a partir de seu insight pedagógico, planos de ensino, prescriçóes e atitudes de expectativa vindas da sociedade. Por outro, eles precisam poder configurar suas aulas de modo a que - para falar com Herbart - o "interesse" das crianças e dos jovens nos conteúdos seja despertado, e eles sejam incitados a "participar" criticamente dos objetos que lhes digam respeito. A dizer a verdade, compreende-se, por si, que só deste modo crianças e jovens poderão tornar-se adultos eticamente formados, capazes de carregar e plasmar politicamente uma sociedade.

Não é de uma Política ou Pedagogia como ciência (moral) prática, que vem a ameaça de um escorregáo no positivismo, senão das Ciências Sociais empíricas - inclusive da Ciência da Educação —, cujo suposto conhecimento dos fatos só pode ainda ser abordado com técnicas sociais. O próprio Schleiermacher mostrou, de modo impressionante, como enunciados afirmativos acerca da pouca inteligência de uma criança podem ser mal-entendidos enquanto fatos, e levar a modos de comportamento do educador de maneira a piorar ainda mais o estado da criança assim classificada, devido ao educador não aproveitar as possibilidades de estimular a criança a tornar-se mais. De modo semelhante, Schleiermacher também mostrou que o professor precisa, sim, conhecer a proveniência social de seus alunos, mas que sua habilidade pedagógica há de 
consistir justamente em não fixar tal proveniência como um dado, senão em tratá-la de tal maneira - e ele fala há quase 200 anos atrás, dentro de uma época ainda inteiramente aristocrática —, que isso um dia poderá vir a ser superado. Com esses dois exemplos eu só gostaria de mostrar que a reivindicação de a Pedagogia ser uma ciência prática tem validade ainda hoje, pois trata-se aí de preparar os futuros pedagogos para situaçốes e exigências pedagógicas de seu tempo, de tal modo que eles consigam reagir a isso não mecanicamente ou fiéis a diretivas, mas com grande responsabilidade pedagógica.

Claudio A. Dalbosco: O que pensa o senhor sobre a ideia da Universidade como centro de Formação humana e profissional em meio aos desafios da sociedade presente? Como o senhor vê a reforma da Universidade alemã após o processo de Bologna? A Universidade atual distanciou-se muito fortemente dos ideais de Humboldt? Isto é: Bolonha substituiu a Bildung?

W. Schmied-Kowarzik: Eu sou naturalmente um defensor da ideia humboldiana de Universidade, hoje ameaçada de ser inteiramente abolida. Devo, porém, a bem da correçáo histórica, acrescentar que o ideal de Universidade de Wilhelm Humboldt já tinha fraquezas elitistas. E, mesmo aqui, o ensaio de Schleiermacher sobre a Universidade — redigido antes de Humboldt defender sua própria ideia e compreeder em uma concepção global um sistema reformado da Educação, desde a Escola primária até a Universidade - é superior ao de Humbodt. Isto se deixa apanhar de modo exemplar precisamente na Pedagogia; pois uma das mais importantes tarefas da então recém-fundada Universidade de Berlim - que se tornou depois o modelo de todas as universidades alemãs - era a formaçáo de professores do Ginásio. É para ela que Wilhelm Humboldt projeta o ideal de cientificidade filosófica, no qual trata-se da ciência da literatura, das línguas e da história, tal como da matemática na Faculdade de Filosofia, isto é, da formação humanística clássica; ao passo que Schleiermacher - e de modo semelhante também Herbart - tem em vista a tarefa do futuro professor desde a Escola fundamental até o Ginásio. Em muitas de suas ideias, Schleiermacher antecipa concepçôes que, mediante aproximação e unificação da formação de professores em Seminários pedagógicos, Academias pedagógicas, Escolas Superiores e Universidades pedagógicas tiveram de ser duramente batalhadas no espaço da língua alemã, no decorrer de mais de 150 anos. $\mathrm{E}$ isso que Schleiermacher não era, de maneira nenhuma, alguém que negasse a cientificidade filosófica; o que ele queria era — como antes Platáo — ligá-la à sua missão prática. $\mathrm{O}$ ethos de todo professor deveria ser um ethos pedagógico, não apenas do professor de Primeiro Grau, pois senão o professor do Ginásio estaria diante dele como mero historiador ou filólogo.

Hoje, nós vivenciamos a lenta imposição precisamente do oposto daquele ideal do professor ginasial. Os cursos das Universidades são reduzidos a um nível de Escola Superior de Ciências Aplicadas e os nobres ideais de unidade 
de ensino e pesquisa são revogados. A pesquisa deve manter-se reservada à Universidade de elite e o ensino da Escola Superior servir apenas à preparação de profissóes mais elevadas. Reage-se, com isso, primeiro, a que se precisa de muito mais formandos de Escolas Superiores nas naçóes industriais e, segundo, a que as promessas democráticas de formação produzem muito mais alunos com o Segundo Grau completo, com direito de acesso à Escola Superior. Desloca-se, assim, às Escolas Superiores e à maioria das Universidades, o que há 100 anos atrás era ainda tarefa dos Ginásios, enquanto a pesquisa puramente científica deve ficar reservada às Universidades de elite e às Instituiçóes de pesquisas especiais, orientadas à economia privada.

Contudo, não é ainda nisso tudo que se encontra o problema, pois o Sistema de Educação precisa naturalmente preparar-se para novos desafios sociais. Aos meus olhos, o problema está em que, em todas as atuais discussões de Reforma Pedagógica, os questionamentos pedagógicos, político-educativos e crítico-científicos não têm mais papel algum. $\mathrm{O}$ que impulsiona as assim ditas Reformas da Educação são perspectivas puramente econômicas, o que vale, na verdade, também para a Escola Primária e até mesmo para o Ensino pré-escolar. Em suma, o Sistema Escolar não tem mais em vista a maioridade de indivíduos que ajam de modo independente, preservando juntos, autonomamente, a sociedade democrática para o bem-estar de todos, senão a formação de forças de trabalho multifuncionais, a fim de otimizar o sistema econômico.

Já em meus últimos anos de atividade na Universidade de Kassel (2006/2007), entrei em contato com as inovaçôes da Reforma de Bologna, mas ainda se podia colocar acentos próprios. Quando, porém, após o meu regresso à Áustria, lecionei dois semestres na Universidade de Viena (2011 e 2012) como professor convidado, pude sentir o total absurdo desse processo europeu de assimilação. Na verdade, os professores ainda se esforçam por manter um ensino de nível universitário; mas a pressão de fora cresce para que seja mediatizada uma base de saber apenas estandardizada, a ser reproduzida e facilmente montável como se fossem cubos de construção. Será assim também, em tempo previsível, nas disciplinas da Pedagogia e da Filosofia, tal como acontece há muito na Administração de Empresas ou na Engenharia, onde o Curso de Bacharelado consiste em apenas quatro anos de duração. Os períodos são numerados meramente de I a IV, porque o conteúdo do ensino permanece sempre o mesmo. Até mesmo o curso de nível "Master" pouco se diferencia desse esquema. Sendo assim, os formandos são preparados para dominar funçóes básicas e, sob instrução de seus superiores em economia e técnica, realizar determinadas tarefas. Aqui, um pensar autônomo ou mesmo objeçóes críticas não são solicitados. Isso talvez pareça vantajoso para a economia privada capitalista, mas terá consequências desastrosas no Sistema da Educação; pois em nossas Escolas e no Ensino Superior foi a ideia de Bildung que prevaleceu, até agora, e seu objetivo foi sempre 
o entendimento autônomo e a livre decisão dos jovens. E isso justamente está sendo maciçamente posto em questão.

Claudio A. Dalbosco: Para finalizar: o que o senhor aconselharia a professores e alunos, no que diz respeito à formação humana, tendo em vista a atual situação (política, econômica e ética)?

W. Schmied-Kowarzik: Como Heinz Joachim Heydorn, sou de opinião que a Teoria da Formação que queira permanecer fiel aos objetivos da tradição filosófico-pedagógica conhecida, só pode ser hoje continuada como Teoria Crítica da Formação. Isto é, só obterá maioridade aquele que conseguir pôr criticamente em questão não apenas o em geral propagado, senão também a si mesmo. Não se trata nisso de uma crítica pela crítica, mas da crítica às situaçóes injustas, crítica ao abuso cometido sobre a natureza e crítica às ideologias propagadoras do ódio. Já a Teoria da Formação, de Johann Amos Comenius, no século XVII, volta-se contra a brutalidade do mundo da Guerra dos 30 anos. Jean-Jacques Rousseau, no século XVIII, deixa que seu Emilio seja criado no campo no intuito de mantê-lo o mais longe possível de influências perniciosas, fazendo-o retornar ao campo outra vez, como adulto, após ter conhecido as intrigas, mentira e corrupção da política dos Estados europeus de então. Friedrich Schleiermacher, por sua vez, torna claro que a Pedagogia não tem de acomodar-se a uma práxis existente, mas que seu fim deve estar sempre voltado a um futuro melhor e mais humano.

Outros pensadores do século XX, como Max Adler, Siegfried Bernfeld, Heinz Joachim Heydorn, e, de certo modo, também Paulo Freire, transportaram esse princípio ao espaço pedagógico. A Pedagogia náo deve aceitar que façam dela o instrumento de uma política economizada, senão, ao contrário, sua tarefa é a de fortalecer os jovens no seu potencial de resistência contra o "mal existente" (Ernst Bloch). Pois, se quisermos sobreviver enquanto humanidade, se quisermos que nossos filhos e netos experimentem a riqueza dessa Terra e a multiplicidade cultural entre os seres humanos, é urgentemente indicado que a Pedagogia tome partido na direção do fim pela "emancipação humana" (Karl Marx) dos jovens; que não se deixe atrelar à carroça da economia capitalista, que destrói o homem e a natureza. Com o quê nós chegamos de volta a Platão, a saber, à consciência de que se náo nos for possível transmitir a ideia do comportamento moral de uma geração à próxima, não haverá jamais uma pólis justa e tampouco uma melhora na história da humanidade. Hoje podemos mesmo acrescentar: não haverá, então, sequer uma sobrevivência humana da humanidade.

\section{Notas}

1. A tradução desta entrevista coube aos profs. M. Maia-Flickinger e H.G. Flickinger, a quem agradeço pela generosa disposição. Também agradeço ao professor Pedro L. Goergen pelas valiosas 
sugestôes. (Nota de Claudio A. Dalbosco. Todas as notas subsequentes serão desta mesma autoria, abreviada, entre parênteses, simplesmente pela sigla CAD).

2. Cabe ressaltar que o prof. Hans-Georg Flickinger, em seus mais de trinta anos de intercâmbio acadêmico entre Brasil e Alemanha, intermediou os estudos de muitos brasileiros na Alemanha, inclusive os meus próprios estudos, e de muitos estudantes alemães no Brasil. Em gratidão a este seu intenso trabalho acadêmico, muitos de seus ex-orientandos e alguns de seus amigos acadêmicos dedicaram-lhe recentemente uma Festschrift (BOMBASSARO \& DALBOSCO \& HERMANN, 2014). (CAD)

3. Neste contexto, justifica-se também sua insistência em refletir questóes relacionadas ao meio ambiente (SCHMIED-KOWARZIK, 2002, p. 97-112; 1999). Na época de meu doutorando em Kassel, eu tinha vários colegas asiáticos, principalmente da Coréia do Sul, que estavam fazendo o doutorado com o prof. Schmied-Kowarzik sobre o conceito de natureza na filosofia alemã, especialmente na tradição do idealismo alemão. (CAD).

4. Dietrich Benner é um dos principais pensadores da filosofia da educação alemã. Uma de suas principais obras intitula-se Haupströmungen der Erziehungswissenschaft (Correntes principais da ciência da educaçáo, 1978). (CAD)

5. Portanto, como se pode observar, Schmied-Kowarzik concebe a Pedagogia como ciência prática, atribuindo-lhe uma dupla função, interligada entre si, como teoria da educação e como teoria da formação. Ao atribuir à Pedagogia esta dupla tarefa - de problematização da açáo humana na perspectiva educacional e de orientação de mundo -, ele a coloca além da perspectiva meramente cognitivista, reduzida ao ensino de competências e habilidades. Vê-se, com isso, a atualidade de suas preocupaçóes educacionais e formativas (CAD).

6. Cabe lembrar que na cidade de Kassel realiza-se, de quatro em quatro anos, a Dokumenta, considerada maior exposição em ar livre de arte na Europa. Este foi um fator que fortaleceu a Escola Superior de Arte. (CAD).

7. Como doutorando tive a oportunidade de frequentar assiduamente as sessôes de estudos e de conferencias ocorridas no âmbito do IAG, durante o perído de 1998 a 2001. Entre os conferencistas tive a oportunidade de ouvir Heinz Paetozold (1995), Michael Hampe (2009), Oskar Negt (1999) e Volker Gerhard (2000). Além de toda o aprendizado interdisciplinar, destacado pelo prof. Schmied-Kowarzik, o IAG oportunizava ao doutorando estrangeiro um exercício genuíno de domínio da linguagem filosófica alemã. (N.E.).

8. Vista na perspectiva filosófica a Pedagogia como ciência prática constitui-se duplamente: como reflexão da práxis existente, que também abarca o agir educativo espontâneo, é teoria da educação; enquanto autoesclarecimento prático dos agentes pedagógicos ela é teoria da formação. (CAD).

9. Encontra-se aqui sem dúvida o núcleo problemático das teorias educacionais modernas, formulado originalmente por Rousseau com a expressão "liberdade bem regrada" e desenvolvida, posteriormente, por outros autores. Kant, antes mesmo de Fichte, reformula o problema, em suas preleçóes Über Pädagogik, nos termos da tensão entre coação (Zwang) e liberdade (Freiheit) (CAD).

10. Vista nesta perspectiva, com uma raiz no pensamento aristotélico, a pedagogia, como ciência prática, insere-se na tradição inaugurada pela phronesis e possui, enquanto tal, do ponto de vista 
sistemático, uma racionalidade ancorada na práxis e não no método experimental fundado pela ciência moderna. Contemporaneamente, a hermenêutica gadameriana também procura fundar a racionalidade na sabedoria prática de raiz aristotélica. (CAD).

\section{Referências}

BENNER, D. Hauptströmungen der Erziehungswissenschaft. Eine Systematik traditioneller und moderner Theorien. München: List Verlag, 1978.

BOMBASSARO, L.C.; DALBOSCO, C.A.; HERMANN, N. (Orgs.). Percursos hermenêuticos e politicos. Homenagem a Hans-Georg Flickinger. Passo Fundo: UPF Editora; Porto Alegre: EDIPUCRS; Caxias do Sul: EDUCS, 2014.

COHN, J. Befrein und Binden. Zeitfragen der Erziehung überzeitlich betrachtet. Leipzig: Quelle \& Meyer, 1927.

FICHTE, J. G. Grundlage der gesamten Wissenschaftslehre. Hamburg: Meiner, 1997.

GEHARD, V. Individualität. Das Element der Welt. München: Beck, 2000.

HAMPE, M. Das vollkommene Leben. Vier Meditationen über das Glück. München: Carl Hanser Verlag, 2009.

IMMLER, H.; SCHMIED-KOWARZIK, W. Marx und die Natur Frage. Ein Wissenschaftsstreit. Kassel: Kassel University Press, 2011.

KANT, I. Sobre a Pedagogia. Piracicaba: Editora Unimep, 2002.

NEGT, O. Kindheit und Schule in einer Welt der Umbrüche. Göttingen: Steidl, 1999.

PAETOLZ, H. Ernst Cassirer. Von Marburg nach New York: Eine philosophische Biographie. Darmstadt: WBG, 1995.

SCHELLING, F.W.J. Ausgewählte Schriften in 5 Bänden. Frankfurt am Main: Suhrkamp, 1995.

SCHLEIERMACHER, F. Texte zur Pädagogik. Kommentierte Studienausgabe, Band 1. Herausgegeben von Michael Winkler und Jens Brachmann. Frankfurt am Main: Suhrkamp, 2000.

SCHMIED-KOWARZIK, W. Sinn und Existenz in der Spätphilosophie Schellings. Wien, 1963. (Dissertation).

. Dialektische Pädagogik. Vom Bezug der Erziehungswissenschaft zur Praxis. München: Deutscher Verlag Studium, 1974.

. Pedagogia Dialética. De Aristóteles a Paulo Freire. São Paulo: Brasiliense, 1983.

. (Hrsg.): Der Philosoph Franz Rosenzweig (1886-1929). Internationaler Kongress

Kassel 1986. Band I: Die Herausforderung jüdischen Lernens. Band II: Das neue Denken und seine Dimensionen. Freiburg/München: Verlag Karl Alber, 1988,

. (Hrsg.): Vergegenwärtigungen des zerstörten jüdischen Erbes. Franz-RosenzweigGastvorlesungen Kassel 1987-1998. Kassel: Studia Cassellana, 1997. 
. Denken aus geschichtlicher Veantwortung. Wegbahnungen zur praktischen Philosophie. Würzburg: Königshausen und Neumann, 1999.

. Práxis e responsabilidade social. Porto Alegre: EDIPUCRS, 2002.

Filosofia prática e pedagogia. In: DALBOSCO, C. A. (Org.). Filosofia prática e pedagogia. Passo Fundo: UPF Editora, p. 29-45, 2003.

. (Hrsg.): Auseinandersetzungen mit dem zerstörten jüdischen Erbe. Franz-RosenzweigGastvorlesungen (1999-2005). Kassel: Studia Cassellana, 2004,

. (Hrsg.): Franz Rosenzweigs „neues Denken“. Internationaler Kongress Kassel 2004. Band I: Selbstbegrenzendes Denken - in philosophos.Band II: Erfahrene Offenbarung - in theologos. Freiburg/München: Verlag Karl Alber, 2006.

Hegel in der Kritik zwischen Schelling und Marx (Hegeliana 24). Frankfurt am Maim: Peter Lang Verlag, 2014.

Existenz denken. Schellings Philosophie von ihren Anfängen bis zum Spätwerk, Freiburg/München: Alber, 2015.

Recebido em 07 de janeiro de 2016.

Aprovado em 16 de fevereiro de 2016. 